\title{
Article
}

\section{ERP evidence suggests executive dysfunction in ecstasy polydrug users}

Roberts, C A, Fairclough, S H, Fisk, John, Tames, F and Montgomery, C

Available at http://clok.uclan.ac.uk/8324/

Roberts, C A, Fairclough, S H, Fisk, John ORCID: 0000-0002-2981-0870, Tames, $F$ and Montgomery, C (2013) ERP evidence suggests executive dysfunction in ecstasy polydrug users. Psychopharmacology, 228 (3). pp. 375388. ISSN 0033-3158

It is advisable to refer to the publisher's version if you intend to cite from the work. http://dx.doi.org/10.1007/s00213-013-3044-6

For more information about UCLan's research in this area go to http://www.uclan.ac.uk/researchgroups/ and search for <name of research Group>.

For information about Research generally at UCLan please go to http://www.uclan.ac.uk/research/

All outputs in CLoK are protected by Intellectual Property Rights law, including Copyright law. Copyright, IPR and Moral Rights for the works on this site are retained by the individual authors and/or other copyright owners. Terms and conditions for use of this material are defined in the policies page. 
ERP evidence suggests executive dysfunction in ecstasy polydrug users

Running Head: executive dysfunction in ecstasy users

Roberts, C. A., Fairclough, S., Fisk, J. E., Tames F. J., \& Montgomery C School of Natural Sciences and Psychology, LJMU

Corresponding Author:

Dr Catharine Montgomery

School of Natural Sciences and Psychology

LJMU,

Tom Reilly Building,

Byrom St,

Liverpool. L3 3AF.

Tel: 00441519046295

Email: c.a.montgomery@ljmu.ac.uk 


\section{Abstract}

Background: Deficits in executive functions such as access to semantic/long term memory have been shown in ecstasy users in previous research. Equally, there have been many reports of equivocal findings in this area. The current study sought to further investigate behavioural and electrophysiological measures of this executive function in ecstasy users. Method: Twenty ecstasy polydrug users, 20 non-ecstasy polydrug users and 20 drug naive controls were recruited. Participants completed background questionnaires about their drug use, sleep quality, fluid intelligence and mood state. Each individual also completed a semantic retrieval task whilst 64 channel EEG measures were recorded. Results: ANOVA revealed no between group differences in behavioural performance on the task. Mixed ANOVA on ERP components P2, N2 and P3 revealed significant between group differences in the N2 component. Subsequent exploratory univariate ANOVAs on the N2 component revealed marginally significant between group differences, generally showing greater negativity at occipitoparietal electrodes in ecstasy users compared to drug naïve controls. Despite the absence of behavioural differences, differences in N2 magnitude are evidence of abnormal executive functioning in ecstasy polydrug users.

Keywords: ecstasy; cannabis; executive function. 
$\underline{\text { Introduction }}$

The recreational drug ecstasy/MDMA (3,4-methylenedioxymethamphetamine) is a potent indirect monoaminergic agonist, that is structurally similar to amphetamine and mescaline (Morgan, 2000). The acute psychological and physiological effects include feelings of euphoria and empathy, increased energy, dilated pupils and tight jaw (trismus) (Davison \& Parrott, 1997) and are thought to result primarily from serotonin and dopamine agonsim (McDowell \& Kleber, 1994). However "ecstasy" has been classed under the novel pharmacological category of entactogens owing to its unique psychoactive profile that can be differentiated from classic hallucinogens and stimulants (Morgan, 2000).

Cognitive deficits have been reported among ecstasy users, and use is associated with working memory and executive functioning impairments (Fisk et al., 2004; Montgomery et al., 2008). Areas involved in working memory and executive function include the dorsolateral prefrontal cortex (DLPFC) and dependent on the nature of the task, the hippocampus. These structures are densely innervated with 5HT neurons (Pazos et al., 1987). As such, degradation to the integrity of this system via neurotoxicity or alternatively downregulation from prolonged use of the drug, may result in deficits in the cognitive functions that these areas maintain. In addition to this, lack of sleep (among other possible lifestyle variables, such as heat and bioenergetic stress), has been suggested to exacerbate or even cause cognitive deficits observed in ecstasy using populations (Cole et al. 2002). Furthermore, Allen et al., (1993) report that characteristics of sleep, such as sleep quality, quantity of hours and related changes in alertness are altered in ecstasy users relative to controls. More recently, Carhart-Harris et al., (2009) found that current and abstinent ecstasy users who reported little use of "other" drugs reported persistent abnormalities in sleep patterns and quality. Nonetheless, deficits in memory have been observed to persist after controlling for sleep and other lifestyle variables (Montgomery et al., 2010). 
The central executive of working memory has been suggested to comprise of four discrete functions rather than being a unified construct (Miyake, et al., 2000). The initial three functions - monitoring and updating of working memory, inhibitory control and mental set shifting proposed by Miyake et al. (2000) were supplemented by a fourth component of "access" to semantic/long term memory added by Fisk and Sharp (2004). This "access" component involves word fluency and the efficiency of lexical access. Retrieval of words and semantics involves the ability to access the long term memory store, and the efficiency with which this can occur seems to be dependent on areas of the DLPFC (Stuss et al., 1998), as well as other subcortical networks (Jokeit et al., 1998). It may not be entirely surprising that word fluency requires long term memory activation, and it has been observed that long term recall is correlated with performance on word fluency tasks (Ruff et al., 1997).

Some studies have been conducted that assess access to semantic memory in ecstasy users using measures such as the Controlled Oral Word Association task (COWA) in which participants have 1 minute to vocalise as many words beginning with $\mathrm{F}, \mathrm{A}$ and $\mathrm{S}$ as possible (see Bhattacharay \& Powell, 2001). Some studies using this measure have yielded deficits in ecstasy users compared to controls (Bhattachary \& Powell, 2001; Fox et al. 2002), whereas others report no such deficits (e.g. Halpern et al., 2004). However, as a written variant of the COWA, the Chicago Word Fluency Test appears to yield more consistent observable deficits in ecstasy users (Montgomery et al., 2005; Montgomery et al., 2007). It remains a possibility that a verbal one minute retrieval task, with no restrictions upon word type or length is too simple to require the involvement of the central executive and as such ecstasy users may not show any impairment on the COWA. It has been noted that ecstasy users have shown impairments on difficult aspects of tasks, yet appear unaffected on simple tasks that require relatively automatic processing (Fox et al., 2002). Consequently further investigation of ecstasy related deficits in access to semantic memory is required. 
Neuroimaging techniques such as electroencephalography, positron electron tomography (PET) and functional magnetic resonance imaging (fMRI) are useful tools for this type of investigation. Firstly, it would be beneficial to observe neurophysiological correlates of behavioural deficits and the underlying mechanisms by which this executive function operates. In addition, due to the necessity for neurophysiological techniques to reduce body movements and vocalisations so that the data is not contaminated with noise, it would be advantageous to develop novel tasks to tap this function as suggested by Murphy et al., (2009). Badre et al., (2005) used fMRI to observe the mechanisms by which semantic retrieval occurs in healthy controls. Participants were presented with a cue word and 3 target words on a screen for 3 seconds. Participants were required to either select a target (by using a keyboard) based on a global relation to the cue (i.e. no judgement made about specific features or dimensions of the words such as shape, colour, semantics) or alternatively based on a specific semantic feature. Stimuli were matched for word length and frequency of presentation; furthermore cue-target associative strength was varied. For example a low semantic associative strength would have a cue word such as "detective" with targets "search, offer and pond" with "search" being the closest to "detective" semantically. An example of high associative strength would be "candle" with the targets "flame, arena and goat" and here it is clear that candle and flame are strongly associated in meaning and as such represent a high associative strength. Badre et al., (2005) posit that prefrontal cortex mechanisms mediate semantic retrieval and that the ventrolateral prefrontal cortex (VLPFC) and middle temporal cortex are sensitive to association strength.

Whitney et al., (2010) investigated the neuronal network involved in semantic retrieval and processing. Strength of semantic association with the cue word low vs. high was used as the manipulation. Transcranial Magnetic Stimulation (TMS) in healthy subjects was employed to disrupt processing in the Inferior Frontal Gyrus (IFG) and the posterior middle 
temporal cortex. Disruption to both of these sites produced attenuation of effective processing of executively demanding processes, however processing of cue-target stimuli with strong semantic association that are relatively automatic - were unaffected by the disruption. It was concluded that there is a network of prefrontal and posterior temporal regions that underlie semantic control, and may provide an explanation why ecstasy users may be unaffected in relatively simple semantic retrieval tasks, such as the COWA.

Indeed electrophyisiological measures such as EEG are more sensitive to detecting impairment than behavioural measures alone. For example, certain behavioural differences may be undetectable due to compensatory mechanisms that are employed to provide support for degraded primary mechanisms. This has been observed in patients with Alzheimer's disease (Rossi et al., 2004). Additionally, Saykin et al. (1998) investigated semantic retrieval in Alzheimer's disease patients with the use of neuroimaging, and observed that they displayed additional activation in frontal regions compared to controls. This is suggestive of compensatory recruitment of additional resources in order to complete the tasks to a similar standard of performance to controls. Similarly using fMRI, Kanayama et al., (2004) reported that cannabis users displayed activation of additional brain regions to those usually observed in a spatial working memory task using fMRI, despite behavioural measures providing no observable differences between them and controls. Here, the results from behavioural measures would indicate that the processes involved in spatial working memory were intact in cannabis users, yet the neuroimaging data suggest recruitment of additional resources. Furthermore Jager et al., (2006) has also reported alterations to left superior parietal cortex activity on working memory tasks in cannabis users despite equivalent behavioural performance to controls on the task. Both studies highlight the possibility of compensatory brain mechanisms underlying undetectable behavioural differences in working memory tasks in cannabis users. We propose that similar mechanisms could operate in ecstasy users. 
EEG is an electrophysiological technique with high temporal resolution that may be beneficial to use in combination with behavioural measures to assess any changes in brain function as a result of ecstasy use in semantic retrieval. Event Related Potentials (ERPs) are ideal for investigating tasks that require executive control, as these tasks require rapid executive decisions that are less detectable with other neuroimaging techniques. Burgess et al., (2011) observed differences between ecstasy users and controls in ERPs in a word recognition task. Ecstasy users showed an attenuation of a late positivity over left parietal scalp sites despite equivalent performance on the task. As such this is suggested to be a durable abnormality in a specific ERP component associated with recollection in ecstasy users that may have not been detected with behavioural measures alone.

The P3 ERP is a positive spike in neuroelectric activity that occurs around 300ms after stimulus onset. This component is thought to be involved in higher level cognitive processing and executive functioning. A diminished P3 potential is understood to reflect cognitive dysfunction. Casco et al. (2005) observed a diminished P3 response in a simple discrimination task in moderate and heavy ecstasy users compared to controls in a visually evoked potential study. Furthermore Gamma et al. (2005) report reductions in the P3 amplitudes of ecstasy users, compared to controls in an inhibitory control (Go-Nogo) task. However it is reported that this effect is diminished after controlling for age, educational level and cannabis use. Indeed the authors suggested that the diminished P3 response could be a polydrug effect given the amount of cannabis use reported by the ecstasy users in their sample. de Sola et al., (2008) conducted a battery of cognitive tests to investigate P3 differences between ecstasy users, cannabis users and controls, they found no significant between group differences on these tasks in P3 latency or amplitude. However there were significant correlations between P3 latency and lifetime cannabis use, whereas Mejias et al., 
(2005) report aberrations in the N2 component in ecstasy users compared to controls in a visual oddball task.

The current study aims to characterise the nature of MDMA's effects on the cognitive processes involved in accessing semantic memory by using EEG measures during a semantic retrieval task similar to that used by Badre et al., (2005) and Whitney et al., (2010). It is hypothesised that behavioural differences will not be present in trials where there is high association between the cue and target word, but that differences will be observed with weaker semantic associations, as the weaker association condition will be more difficult, requiring induction of the central executive. Similarly it is hypothesised that there will be differences in electrophysiological measures that reflect higher level processing (e.g. P3, N2) whereby ecstasy users display aberrant electrophysiological behaviour compared to nonusers.

\section{Method:}

\section{Design:}

In all analyses, a mixed design was used with a between groups factor of drug user group with 3 levels (ecstasy user, non-ecstasy polydrug user and drug naive controls) and associative strength (High vs. Low) as a within subjects factor. Mixed ANOVA was conducted on the behavioural data with the scores on the semantic association tasks as the dependent variable. ERP data was analysed using mixed ANOVA with drug user group as the between subjects factor and site of electrode (PO7, PO3, O1, OZ, POZ, PO8, PO4 and $\mathrm{O} 2$ for the $\mathrm{N} 2$ and $\mathrm{P} 3$ components and sites FZ, FCZ, FC1, FC2, CZ, C1 and $\mathrm{C} 2$ for the P2 component) as well as associative strength (high vs. low) as the within groups factors. Mean 
amplitudes at the 3 ERP components were the dependent variables. Where appropriate, significant main effects were further investigated using univariate ANOVA.

\section{$\underline{\text { Participants: }}$}

Twenty ecstasy users (mean age $=23.95, \mathrm{SD}=0.57,10$ male), 20 non-drug user controls (mean age $=23.1, \mathrm{SD}=0.66,7$ male) and 20 non-ecstasy drug user controls (mean age $=$ $22.58, \mathrm{SD}=0.79,9$ male) were recruited via direct approach to university students and club goers. In terms of statistical power, with 20 participants in each of the three groups, the sample is sufficient to detect a difference between pairs of means of at least 1 standard deviation at alpha $=.05$ and beta $=.20$ (Hinkle et al., 1994). The additional control group of participants that have not used ecstasy previously, yet have used other illicit substances was recruited to address the issue of polydrug use as a potential cause for the cognitive deficits observed.

To avoid age related deficits in working memory obscuring pharmacologically derived deficits age range for inclusion was 18-29 years. Inclusion in the ecstasy user group required participants to have taken ecstasy/MDMA on 5 or more occasions over their lifetime (actual minimum $=5$ ecstasy tablets). Furthermore for inclusion in both control groups participants must have never used ecstasy/MDMA, however all other illicit substances were permitted for the non-ecstasy poly drug user control group.

All participants were asked to abstain from consuming ecstasy for a minimum of 7 days prior to testing and urine samples were collected upon arrival to the lab for urinary analysis of all drug metabolites, to confirm abstinence (after ingestion MDMA is generally accepted to be detectable in urine for 1-3 days, this is the same for cocaine and amphetamines, with cannabis being detectable for anything up to 95 days Verstraete, 2004). Participants were also 
requested to abstain from use of other illicit drugs for a minimum of 24 hours prior to participating and ideally for 7 days.

\section{$\underline{\text { Materials }}$}

Upon entering the lab participants completed a background drug use questionnaire, which provides the researcher with indices of drug use patterns and other lifestyle variables. Comprehensive details of ecstasy use as well as other illicit drug use were requested, such as first and last drug use, patterns of drug use, frequencies and doses over time. Using a method employed by Montgomery et al. (2005) estimates of total lifetime drug use of each drug were calculated. Totals for last 30 days drug use as well as weekly drug use estimates were also calculated. This questionnaire also sought information about health, age, years of education and perceived changes to mood and cognition amongst other lifestyle variables.

\section{$\underline{\text { Measures of Sleep Quality }}$}

Sleep quality and alertness were measured to investigate any possible relationship between sleep quality and cognition using the following questionnaires; a sleep quality questionnaire, exploring typical quantities of sleep (how many hours slept typically, how many hours over the last 3 nights) and level of quality of sleep. The Epworth Sleepiness Scale (ESS, Johns, 1991), explores the chances of dozing or falling asleep in various situations such as "sitting and reading" and "sitting quietly after lunch without alcohol", and is scored from $0=$ would never doze off to $3=$ High chance of dozing. A high total score here is indicative of increased subjective daytime sleepiness. The Morningness-Eveningness Questionnaire - self assessment version (MEQ, Terman, Rifkin, Jacobs \& White, 2001) is a self assessment of morningness-eveningness in human circadian rhythms (originally developed by Horne \& 
Östberg, 1976), a high score on this questionnaire is indicative of a morning type person and a low score is indicative of an evening type person. Finally the Karolinska Sleepiness Scale (Akerstedt \& Gillberg, 1990), is a self assessment of sleepiness at the current moment in time (ranging from $1=$ extremely alert, to $9=$ extremely sleepy, fighting sleep, effort to stay awake), therefore this can be administered at different time points of the experiment to assess sleepiness. As such this was administered to participants pre and post task.

\section{State Mood.}

State Anxiety, Arousal and Depression were measured using scales devised by Fisk \& Warr (1996). Participants are required to rate on a 5 point likert scale from $1=$ not at all, to $5=$ extremely, how they are feeling at the time of testing. A high score on each subscale indicates increased hedonic tone/anxiety/arousal.

\section{$\underline{\text { NASA-TLX (Hart et al. 1988) }}$}

Finally, a questionnaire measuring subjective workload was given post task. This is a multidimensional scale, consisting of six sub-scales (mental demand, physical demand, temporal demand, personal performance rating, effort and frustration). Participants were required to place a mark on a $100 \mathrm{~mm}$ line, indicating where they perceive their demand to be on the scale. These are taken to observe whether there are any differences between ecstasy users and non users in perceived cognitive demand on the task. It has been reported that ecstasy users may be more susceptible to stress than non-users and may thus report increased cognitive effort (Wetherell et al., 2012).

\section{Access to Semantic Memory}

The executive function "access" was assessed using a semantic association task that is based around the tasks used by Whitney et al. (2011) and Badre et al. (2005), whereby 2 types of 
semantic judgement which differed in their level of difficulty (high association/low association) were used. In both difficulty levels participants were presented with a cue word in the centre of a computer monitor followed by three target words, one which had a semantic association with the cue, and two distracters. Participants had to decide which of the three target words had the strongest semantic association with the cue word. They selected their answer by pressing one of three buttons on a response box which corresponded to their position on screen. They were either high association between cue and target words (e.g. candle - flame) or low association (e.g. detective - search). The low association judgement is deemed to be more difficult and require more processing than the relatively automatic high association semantic judgements. As such the low association between cue and targets leads to a less obvious dissociation from distracters requiring recruitment of additional executive resources in the semantic network (Whitney et al., 2011). The stimuli used were matched for word length, frequency and cue-target association strength (Badre et al., 2005; Whitney et al., 2011) and were kindly provided by Whitney et al. The task consisted of a practise round followed by 4 blocks of 30 trials, with both high and low association trial types appearing in each block pseudo-randomly ( 15 of each in each block). The cue word was presented for 1 second in the centre of a computer screen. After this the three target words appeared below aligned to the left, centre and right of the monitor. Participants were instructed to respond via pressing a button on the response box corresponding to the position of the target on the screen (left, centre, right). The targets remained on screen until a response was made or until the trial timed-out (time out set to 8.5 seconds). An inter trial interval of 2 seconds was employed. The task took around 20 minutes to complete. Participants were instructed to respond as quickly and as accurately as possible. 


\section{Equipment}

EEG was recorded using a 64 channel Biosemi $\mathrm{Ag}-\mathrm{AgCl}$ active-two electrode system (Biosemi B.V, Amsterdam, Netherlands) with pin type electrodes mounted in a stretch-lycra headcap (Biosemi) and positioned according to the international 10-20 system. Neuroelectric activity was recorded from the following sites: frontal (FPz, FP1, FP2), anterior-frontal (AFz, AF3, AF4, AF7, AF8), frontal (Fz, F1, F2, F3, F4, F5, F6, F7, F8), frontocentral (FCz, FC1, FC2, FC3, FC4, FC5, FC6), central (Cz, C1, C2, C3, C4, C5, C6), temporal (FT7, FT8, T7, T8, TP7, TP8), parietocentral (CPz, CP1, CP2, CP3, CP4, CP5, CP6), parietal (Pz, P1, P2, P3, P4, P5, P6, P7, P8, P9, P10), occipitoparietal (POz, PO3, PO4, PO7, PO8) and occipital (Oz, O1, O2, Iz). Sigma electrolyte gel was used to ensure contact between scalp and electrodes. Vertical and horizontal electro-occulograms were recorded using bipolar, flat $\mathrm{Ag}-\mathrm{ACl}$ electrodes positioned above and below the left eye as well as to the outer side of each eye. Data was digitized at a sampling rate of $512 \mathrm{~Hz}$ and no filters were applied online so that the data could be visually inspected for noise and offline filtering could be performed.

\section{Procedure}

Testing sessions commenced at 9.30 a.m or 1.30 p.m, and equal numbers of participants from each condition were tested in the morning and the afternoon. Upon entering the lab, participants were given a brief description of the experiment and written informed consent was obtained. Following this, participants gave a urine sample which was immediately frozen at -25 Celsius. Participants then completed the battery of questionnaires, whilst their head circumference and other details were measured, and an electrode cap and electrodes were fitted. The questionnaires were administered in the following order: Background drug use questionnaire, Morningness-Eveningness questionnaire, sleep quality questionnaire, State Mood, Epworth Sleepiness Scale, Karolinska sleepiness scale (before) and fluid intelligence 
was assessed using Raven's Progressive Matrices (Raven, Raven \& Court, 1998). Following completion of these questionnaires, the EEG setup was checked and if necessary modified. Participants then completed the computerised task on a desktop computer running Inquisit version 3.0.6.0 (Millisecond Software, 2011). The NASA-TLX questionnaire was completed after the task as was the post task Karolinska sleepiness scale. Finally participants were fully debriefed and paid $£ 20$ in store vouchers. The study was approved by Liverpool John Moores University Research Ethics Committee, and was administered in accordance with the ethical guidelines of the British Psychological Society.

\section{EEG Analysis}

The EEG data was analysed using BESA 5.3 (MEGIS software GmbH, Gräfelfing, Germany). All recordings were visually analysed offline, using high and low pass filters of $0.1 \mathrm{~Hz}$ and 40 $\mathrm{Hz}$ respectively. Any channels judged to be bad were replaced by interpolation and all data were EOG-corrected using BESAs PCA based algorithm. All trials judged to be bad after this point were discarded. EEG was segmented into epochs from -500 to $1000 \mathrm{~ms}$ from time of stimulus onset. Epochs were time-averaged by stimulus type so that ERPs for correctly and incorrectly identified stimuli in each condition of each task (e.g. correct "high associations" and incorrect "high associations" and correct "low associations" and incorrect "low associations") could be generated for each individual. Only ERPs for correct responses were included in the subsequent analysis. There were 120 trials in total, the mean number of good trials retained for grand averaging per subject was 109.66 (average of $8.6 \%$ rejected trials), after rejecting incorrect trials $(6.1 \%)$ and those containing artefacts $(2.5 \%)$. Grand averages were made for each group (ecstasy user, polydrug user and drug naïve) on each condition 
(correct "high associations", correct "low associations"). The overall P3 response was defined as the mean amplitude between 280 and $350 \mathrm{~ms}$, for the low association condition and 250-350ms for the high association condition. These time windows were centred on the positive peak latency and the duration was chosen due to this epoch containing the majority of positive activity for all conditions by observing topographic maps (See Figures $1 \& 2$ ). Electrode activity was analysed in this epoch from occipitoparietal and occipital electrodes PO7, $\mathrm{PO} 3, \mathrm{O} 1, \mathrm{OZ}, \mathrm{POZ}, \mathrm{PO} 4, \mathrm{PO} 8$ and $\mathrm{O} 2$, as the greatest amount of activity in the $\mathrm{P} 3$ component could be observed at these sites. Further components were also analysed for between group differences, including the $\mathrm{N} 2$ and $\mathrm{P} 2$ components. The $\mathrm{N} 2$ component was also largest over occipitoparietal and occipital electrodes (PO7, PO3, O1, OZ, POZ, , PO4, PO8 and O2), between $120-190 \mathrm{~ms}$ in the low association condition and $120-200 \mathrm{~ms}$ in the high association condition, again epochs were based around the mean local negative peak at these sites and encompassed the majority of negative activity over all 3 groups. The P2 component was most visible as a positive peak between 170 and 230ms (for both low and high association) at anterior and midline sites (FZ, FCZ, FC1, FC2, CZ, C1 and C2) the mean amplitudes at these sites from the epochs based around the peaks from the grand averages of all conditions were analysed.

<<Insert Figures $1 \& 2$ About Here〉>

\section{$\underline{\text { Urinary Analysis }}$}

Frozen urine samples were delivered to University Hospitals Aintree and were analysed using Solid Phase Extraction (Mixed Mode Phase) followed by Reverse Phase HPLC MS/MS detection using BOTH Positive \& Negative Ion Multiple Reaction Monitoring (MRM). Urine Specimens have been tested for: the Synthetic Cannabinoids (JWH-018, JWH-073, JWH-250, 
JWH-398, JWH-122, JWH-019, AM-694, WIN 48098 \& WIN-55212-2), as well as the 'designer' drugs 'Mephedrone', bk-MDMA or 'Methylone', bk-MBDB or 'Butylone', bkPMMA or 'Methedrone', 1-benzylpiperazine, TFMPP, mCPP and MDPV. Also tested for were a series of 12 Piperazine compounds, $4 \beta$-Keto Amphetamines, a series of 11 Methcathinone compounds, 4-Fluoroamphetamine, Bupropion \& the Hallucinogenic Amphetamines: D.O.B. ('bromo-STP' or 'Brolamphetamine'), D.O.C. and D.O.I. Finally, 'traditional' drugs of abuse: Amphetamine(s) including M.D.M.A., M.D.A. \& M.D.E.A., Barbiturates, Benzodiazepines, THC \& Cannabinoids, Buprenorphine, Cocaine \& metabolites, Methadone \& metabolites, Opiates \& Opioids (Morphine, Codeine, Dihydrocodeine, Tramadol, d-Propoxyphene, Oxymorphone \& Oxycodone), LSD, G.H.B. (and the Lactone Precursor), Psilocybin, Ketamine and Methaqualone were tested for as well.

\section{$\underline{\text { Results }}$}

Table 1 shows indices of ecstasy use from the ecstasy user group, including total lifetime dose (tablets), total number of tablets taken in the last 30 days and frequency of use (times per week).

\section{$<<$ Insert Table 1 Here >>}

Participants' socio-demographic information, state mood scores from the mood adjective checklist and sleep measures are shown in Table 2, and indices of other drug and alcohol use are displayed in Table 3.

\section{$<<$ Insert Tables $2 \& 3$ Here $>>$}

One way ANOVA revealed that there were no significant between group differences on measures such as age, average hours sleep per night, total score on the Epworth Sleepiness Scale, Morningness-Eveningness questionnaire total score, post test Karolinska sleepiness 
scale, levels of arousal, depression and anxiety or total score on Ravens Progressive Matrices. However there were between group differences in the pre testing Karolinska sleepiness scale (i.e. how sleepy the participants felt before the test battery) $F(2,58)=3.78, p<0.05$, planned comparison t-tests revealed that the ecstasy user group felt significantly more sleepy prior to testing than the polydrug control group $t(38)=2.39, p<.05$, but not the drug naïve control group $t(37)=0.50, p>.05$.

t-tests between the ecstasy user group and the polydrug-non-ecstasy group revealed that the ecstasy user group had a significantly larger lifetime total of joints smoked than the non ecstasy drug users (5057.88 compared to 1091.71) $t(17.88)=2.02, p<.05$ (Levene's test was significant so degrees of freedom have been adjusted accordingly). The ecstasy users had also smoked significantly more joints within the last 30 days $(32.77$ compared to 6.09) $t(16.01)=$ $1.86, p<.05$. There were however no differences between these two groups on other drug intake variables. However as can be seen from Table 3, the ecstasy user group can be described as polydrug users.

\section{$\underline{\text { Urinary Analysis }}$}

The metabolites detected in the urinary analysis are displayed in Table 4.

$$
<<\text { Insert Table } 4 \text { Here }>
$$

Drug metabolites detected were restricted to cannabinoids, TFMPP and BZP, and were relatively low level. Exclusion of participants with cannabinoid metabolites in their urine did not change the behavioural or electrophysiological analyses so analyses reported include these participants.

\section{$\underline{\text { Behavioural Data Analysis }}$}


The semantic association was programmed in Inquisit version 3.0.6.0 (Millisecond software, 2011) and was analysed using SPSS (17). Incorrect answers in each case were given a score of 0 and were not investigated any further for reaction time analysis. Mean reaction times were calculated for correct high association trials as well as correct low association trials. Reaction time data reduction involved excluding reaction times less than $200 \mathrm{~ms}$ and greater than $5000 \mathrm{~ms}$ as these reaction times represent pre-emptive responding and a loss of concentration respectively. Furthermore individual trial reaction times that were more than 3 standard deviations above the individual mean were discarded. The mean percentage of outliers that were discarded from each group were; ecstasy users $1.46( \pm 0.66)$, polydrug users $1.42( \pm 1.05)$, drug naïve $1.71( \pm 0.92)$, there were no between group differences in amount of outliers $F(2,57)=0.63, p>.05$,

Performance on the semantic retrieval task was measured both in terms of number of errors made (incorrect responses) and reaction time. A mixed ANOVA was conducted with between subjects factor of group and within subjects factor of difficulty (high association and low association). Using error count as the dependent variable there was no significant effect of difficulty $F(1,57)=0.04, p>.05$ (sphericity assumed), no main effect of group $F(2,57)=$ $1.56, p>.05$ and no group by difficulty interaction $F(2,57)=0.01, p>.05$ (Table 5). Similarly using reaction time as the dependent variable no significant between group differences were observed $F(2,57)=0.07 p>.05$. Difficulty and group by difficulty interactions were non significant $p>.05$ in both cases (Table 5).

Post task NASA TLX scores were analysed using a multivariate analysis of variance MANOVA. This revealed no overall between group differences in perceived demand $F(12$, $104)=0.94, p>.05$ for Pillai's trace, nor any between group differences on the individual subscales of their subjective perception of subjective workload (Mental demand; $F(2,56)=1.06$, $p>.05$, Physical demand; $F(2,56)=0.10, p>.05$, Temporal demand; $F(2,56)=1.56, p>.05$, 
Effort; $F(2,56)=0.48, p>.05$, Performance; $F(2,56)=2.62, p>.05$, Frustration; $F(2,56)=$ $0.77, p>.05)$

\section{$\underline{\text { ERP analysis }}$}

The grand average waveforms for each group (users, polydrug non-users and drug naïve controls) can be observed for electrodes PO7, PO3, O1, OZ, POZ, PO8, PO4 and $\mathrm{O} 2$ in Figure 3 (high association) and Figure 4 (low association). Mean amplitudes for each condition and electrode are given in Table 6. Due to some unusable EEG data, 1 participant is excluded from statistical analysis on the EEG data, from the drug naïve group $(n=19)$.

A mixed ANOVA, with between subjects factor of group and within subjects factors of difficulty (high association and low association) and site (FZ, FCZ, FC1, FC2, CZ, C1 and C2) was conducted on the mean amplitudes across the epochs measured (170-230ms in both conditions) for the $\mathrm{P} 2$ component. This revealed, no main effect of difficulty $F(1,56)=0.32$, $p>.05$, no difficulty by group interaction $F(2,56)=0.35, p>.05$, no main effect of site $F(4.21$, $236.03)=5.22, p>.05$, no site by group interaction $F(8.43,236.03)=0.26, p>.05$, no difficulty by site interaction $F(4.85,271.44)=0.51, p>.05$ and no difficulty by site by group interaction $F(9.69,271.44)=0.48, p>.05$ (degrees of freedom adjusted in line with Greenhouse Geisser statistic in all cases). Between group differences were also nonsignificant $F(2,56)=1.68, p>.05$.

A mixed ANOVA, with between subjects factor of group and within subjects factors of difficulty (high association and low association) and site (PO7, PO3, O1, OZ, POZ, , PO4, PO8 and O2) for the mean amplitudes across the epochs measured (120-190 ms in the low association condition, $120-200 \mathrm{~ms}$ in the high association condition) on the $\mathrm{N} 2$ component revealed no main effect of difficulty $F(1,56)=1.05, p>.05$, no difficulty by group interaction $F(2,56)=0.04, p>.05$, no main effect of site $F(3.82,213.92)=6.37, p>.05$, no site by group 
interaction $F(7.64,213.92)=1.10, p>.05$, no difficulty by site interaction $F(4.78,267.40)=$ $0.81, p>.05$ and no difficulty by site by group interaction $F(9.55,267.40)=0.73, p>.05$ (degrees of freedom adjusted in line with Greenhouse Geisser statistic in all cases). Between group differences approached significance $F(2,56)=2.78, p=.07$. In line with apriori predictions and to further explore this trend on the N2 component, Helmert contrasts were performed. The Helmert contrasts revealed a significant difference between the ecstasy polydrug user group and the drug naïve participants, Contrast estimate $=-2.10, \mathrm{p}<.05$. Consequently, univariate ANOVA was conducted between drug naïve participants and ecstasy polydrug users alone, with amplitude at each site as the dependent variable to explore the significant contrast. In the low association condition significant differences were observed at electrode site $\mathrm{O} 1 \mathrm{~F}(1,37)=3.37, \mathrm{p}<.05 ;$ site $\mathrm{OZ} \mathrm{F}(1,37)=3.41, \mathrm{p}<.05 ; \mathrm{PO} 8 \mathrm{~F}(1,37)=6.32$, $\mathrm{p}<.01 ;$ PO4 $\mathrm{F}(1,37)=3.42, \mathrm{p}<.05$ and $\mathrm{O} 2 \mathrm{~F}(1,37)=7.02, \mathrm{p}<.01$. In the high association condition significant differences were observed at site PO3 $\mathrm{F}(1,37)=3.62, \mathrm{p}<.05 ; \mathrm{OZ} F(1,37)$ $=5.05, \mathrm{p}<.01 ; \operatorname{POZ} \mathrm{F}(1,37)=2.83, \mathrm{p}<.05 ; \operatorname{PO} 8 \mathrm{~F}(1,37)=5.56, \mathrm{p}<.01 ; \operatorname{PO} 4 \mathrm{~F}(1,37)=2.84$, $\mathrm{p}<.05$ and $\mathrm{O} 2 \mathrm{~F}(1,37)=4.17, \mathrm{p}<.05$. In all cases, ecstasy users showed a greater negativity than drug naïve controls (Table 6).

A mixed ANOVA, with between subjects factor of group and within subjects factors of difficulty (high association and low association) and site (PO7, PO3, O1, OZ, POZ, , PO4, PO8 and O2) on the P3 component for the mean amplitudes across the epochs measured (280-350 $\mathrm{ms}$ in the low association condition, 250-350 $\mathrm{ms}$ in the high association condition) revealed no main effect of difficulty $F(1,56)=0.71, p>.05$, no difficulty by group interaction $F(2,56)=0.60, p>.05$, no main effect of site $F(4.18,233.99)=13.97, p>.05$, no difficulty by site interaction $F(3.42,191.64)=1.56, p>.05$ and no difficulty by site by group interaction $F(6.84,191.64)=0.61, p>.05$. However there was a significant site by user group interaction $F(8.36,233.99)=1.65, p \leq .05$ (degrees of freedom adjusted with Greenhouse Geisser statistic 
in all cases). There were no significant between group effects $F(2,56)=0.74, p>.05$, so these were not investigated further. To further explore the site by user group interaction, a series of univariate ANOVAs were run with group as the between groups variable and amplitude at the various sites as the dependent variable. This yielded no significant differences between the three groups and no significant post hoc comparisons, $\mathrm{p}>.05$ in all cases.

\section{Discussion}

The current study investigated the executive function of access to semantic memory and its behavioural and electrophysiological correlates. Background variables such as fluid intelligence, age, measures of sleep, level of arousal, depression and anxiety showed no significant differences between the three groups. There were no behavioural differences between groups in terms of number of errors on task and reaction time to correct responses. Furthermore ecstasy users did not differ significantly to the control groups with respect to subjective mental workload.

The electrophysiological data provide support for abnormal executive functioning in ecstasy-polydrug users. In the N2 component, although there were no main effects of difficulty or site, or any interactions with these and group, or difficulty by site by group, there were between group trends that warranted further exploration. In the low association condition of the task ecstasy users displayed a significantly larger negativity in the N2 (120200ms) component compared to drug naïve controls in occipital electrode sites $\mathrm{O} 1, \mathrm{O} 2$ and OZ and occipitoparietal electrode sites PO8 and PO4 compared to drug naïve controls (Fig. 4), although non-ecstasy polydrug users did not differ from either group.

The supposedly easier "high association" condition showed significant differences in negativity at the $\mathrm{N} 2$ component in ecstasy users compared to drug naïve controls at occipital electrode sites $\mathrm{OZ}$ and $\mathrm{O} 2$, as well as occipitoparietal sites PO2, PO3, PO4 and PO8 (Fig. 3). 
Components that reflect positivities (P2 and P3) showed no main effects of difficulty or site, or any interactions with these and group, or difficulty by site by group (except in P3 where there was a site by group interaction) and there were no between group differences. Thus these components are less informative about access to semantic memory in ecstasy users. However, the group difference in the $\mathrm{N} 2$ component does provide some interesting points to consider.

The N2 component has been reported as having a source in the anterior cingulate cortex (Bekker et al., 2005; Nieuwenhuis et al., 2003; Van Veen \& Carter, 2002) and to reflect neural processes engaged during conflict monitoring, thus being increased in high conflict trials (Yeung \& Cohen, 2006), for example when incongruence between targets and cues/distracters elicits a conflict of response in a Stroop task (Kopp et al., 1996). Firstly, considering why the $\mathrm{N} 2$ was more pronounced in ecstasy users compared to drug naïve controls in those trials where there was a lower semantic association between target and cue words, it is possible that at this level of processing, the ecstasy users required the recruitment of additional resources in order to access the semantic network of long term memory compared to drug naïve controls. Previous research has provided evidence that ecstasy users' performance can be more greatly impaired under higher task difficulty. For example Montgomery et al., (2005) observed a decline in performance in a word fluency task when more rules were imposed, suggesting that deficits are more prominent in tasks that place more demand on the central executive. Moreover, given that participants reported no perceived differences in cognitive effort on the NASA-TLX it is possible that compensatory cognitive processing at neurological sites is correcting for deficits in executive function to eradicate behavioural differences and other research reporting null results, with respect to performance may reflect similar reallocation of cognitive resources. This aspect of the results was in line with our predictions. 
However ecstasy users also displayed a greater negativity compared to drug naïve controls in the high association condition of the task, suggesting perhaps that is controlled processing in general that is impaired regardless of task difficulty. It is generally accepted (Jefferies et al., 2004; Rossell et al., 2001; Shiffrin \& Schneider 1977) that information processing involves two modes of processing; automatic and controlled. Controlled processing, unlike automatic processing, involves selectively and consciously attending to a stimulus, suggesting that controlled processing involves higher level mental processes. As such, automatic processing is proposed to rely on long-term memory, whilst controlled processing loads more on working memory (Jeffries et al. 2004), suggesting separable neural substrates. Indeed Rossel et al., (2001) used fMRI to investigate differences in effortful and automatic processing in a similar lexical decision priming experiment, and found that distinct sub regions of the anterior cingulate cortex showed activation dependent on the processing type involved. The $\mathrm{N} 2$ component in a semantic classification task was argued to reflect controlled processing by Ritter et al. (1982). Perhaps any early automatic processing (such as that observed in the P2 component), is unaffected by drug use, whereas such higher level controlled processes are more affected. Indeed perhaps the N2 is the earliest stage at which controlled processing is detectable, and recruitment of additional resources at this stage could offset any further modulation of the waveform in later components such as the P3. Consequently, while we hypothesised that controlled processing and recruitment of the central executive would be elicited only in the low association condition, based on the results it is likely that the task was demanding enough to recruit executive resources in both conditions.

While the above discusses possible $\mathrm{N} 2$ related differences in access to semantic memory, it is indeed possible that the $\mathrm{N} 2$ in the present study reflects changes in other cognitive processes additional to semantic access (See Folstein \& van Petten, 2008, for 
review). The $\mathrm{N} 2$ in the present study was prominent in more posterior electrodes which Suwazono et al. (2000) suggest is reflective of increased attention demands in the visual cortex required for stimulus processing. In this study, posterior N2 was eliminated by eliminating target novelty (i.e. making targets completely predictable). Moreover Luck and Hillyard (1994) investigated subcomponents of the N2 component using visual search tasks. It was found that the bilateral posterior $\mathrm{N} 2$ as seen in the present study was related to visual search and target probability, with an increased posterior N2 when participants could not predict a target before presentation. Taken together this provides tentative evidence that in the present study the posterior N2 may reflect increased demands on visual search and maintenance of visual representations, with greater negativity in ecstasy polydrug users showing that they require increased attentional resources for this.

As with most studies on cognitive deficits relating to ecstasy use, there are some limitations which necessitate a degree of caution when interpreting the data. For example, despite controlling for the use of other drugs, by introducing a polydrug control group (namely cannabis users) that had never taken ecstasy, the ecstasy users in this study smoked significantly more cannabis that the polydrug group. The ecstasy user group also reported consuming more cocaine than the polydrug group. As such any observed differences could still be attributed to the use of these other drugs, or indeed a synergistic effect of concomitant use of other drugs. Perhaps any effects here could be better described as a result of polydrug use, especially given that ecstasy users, although showing greater negativities in the $\mathrm{N} 2$ in both conditions of the task, compared to drug naïve controls were not significantly different to polydrug controls.

Studies that employ quasi-experimental designs cannot exclude the chance that individual differences may belie any observable effect other than drug use. We attempted to control for many of these individual differences, such as sleep quality, fluid intelligence and 
levels of arousal, depression and anxiety. Another limitation lies in self reports of background drug use, which may not be completely accurate due to the problematic recall of drug users. However this is the most appropriate method of investigating drug use and executive function, given the legal status of the drug. Moreover this method is commonly used in the literature (Fox et al., 2001; Montgomery et al., 2005; Montgomery et al., 2010). The purity of the ecstasy tablets consumed, as well as the cocaine purity and cannabis strength are all questionable and cannot be guaranteed. However Parrott (2004) reported that the ecstasy tablets collected from amnesty bins in nightclubs in the UK was approaching $100 \%$ purity. If this is incorrect however, and the purity is in fact, much lower, perhaps this raises additional concerns about the cognitive effects observed (Montgomery et al., 2010).

The present study provides evidence for changes in electrophysiology in ecstasy/polydrug users. Durable abnormalities of the N2 component observed over occipital and occipitoparietal sites of drug users compared to drug naïve controls is suggestive of compensatory mechanisms, or reallocation of cognitive resources that are deployed to attenuate any observable behavioural differences caused by ecstasy related disturbances to traditional processing of semantic information and allocation of attention during visual search. 
References

Akerstedt, T., \& Gillberg, M (1990). Subjective and objective sleepiness in the active individual. Inernational Journal of Neuroscience, 52, 29-37.

Badre., D., Poldrack, R.A., Pare-Blagoev, E.J., Insler, R.Z., \& Wagner, A. (2005). Dissociable controlled retrieval and generalized selection mechanisms in ventrolateral prefrontal cortex. Neuron, 47, 907-918.

Bekker, E. M., Kenemans, L.J., Verbaten, M.N. (2005). Source analysis of the N2 in a cued Go/NoGo task. Cognitive Brain Research, 22(2), 221-231.

Bhattachary, S., \& Powell, J.H. (2001). Recreational use of 3,4-

methylenedioxymethamphetamine (MDMA) or ecstasy: evidence for cognitive impairment. Psychol Med, 31, 647-658.

Burgess, A. P., Venables, L., Jones, H., Edwards, R., \& Parrott, A.C. (2011). Event related potential (ERP) evidence for selective impairment of verbal recollection in abstinent recreational methylenedioxymethamphetamine ("Ecstasy")/polydrug users.

Psychopharmacology, 216, 545-556.

Carhart-Harris, R. L., Nutt, D. J., Munafo, M., \& Wilson, S. J. (2009). Current and former ecstasy users report different sleep to matched controls: a web-based questionnaire study. Journal of Psychopharmacology, 23(3), 249-257.

Casco, C., Forcella, M.C., Beretta, G., Griego, A., \& Campana, G. (2005). Long-term effects of MDMA (Ecstasy) on the human central nervous system revealed by visual evoked potentials. Addiction Biology, 10, 187-195.

Cole, J., Sumnall, H.R., \& Grob, C.S. (2002). Sorted: Ecstasy facts and fiction. The Psychologist, 15(9), 464-467.

Davison, D., \& Parrott, A.C. (1997). Ecstasy (MDMA) in recreational users: Self-reported psychological and physiological effects. Human Psychopharmacology, 12, 221-226.

de Sola, S., Tarancon, T., Pena-Cassanove, J., Espadaler, J.M., Langohr, K., Poudevida, S., Farre, M., Verdejo-Garcia, A., de la Torre, R. (2008). Auditory event-related potentials (P3) and cognitive performance in recreational ecstasy polydrug users: evidence from a 12-month longitudinal study. Psychopharmacology, 200, 425-437.

Fisk, J. E., Montgomery, C., Murphy, P., \& Wareing, M. (2004). Evidence for executive deficits among users of MDMA (Ecstasy). British Journal of Psychology, 95, 457-466.

Fisk, J. E., Sharp, C.A. (2004). Age-related impairment in executive functioning: updating, inhibition, shifitng and access. Journal of Clinical and Experimental Neuropsychology, 26(7), 874-890.

Folstein, J.R., \& Van Petten, C. (2008). Influence of cognitive control and mismatch on the N2 component of the ERP: A review. Psychophysiology, 45, 152-170 
Fox, H. C., Parrott, A.C., \& Turner, J.J.D. (2001). Ecstasy use: Cognitive deficits related to dosage rather than self-reported problematic use of the drug. Journal of Psychopharmacology, 15(4), 273-281.

Gamma, A., Brandeis, D., Brandeis, R., Vollenweider, F.X. (2005). The P3 in 'ecstasy' polydrug users during response inhibition and execution. Journal of Psychopharmacology, 19(5), 504-512.

Halpern, J. H., Harrison, G.P, Jr., Sherwood, A.R., Barry, S., Hudson, J.I., \& Yurglun-Todd, D. (2004). Residual neuropsychological effects of illicit 3,4methylenedioxymethamphetamine (MDMA) in individuals with minimal exposure to other drugs. Drug and Alcohol Dependence, 75, 135-147.

Hart, S. G. S., L.E. (Ed.). (1988). Development of NASA-TLX (Task Load Index): Results of empirical and theoretical research. Amsterdam: North Holland.

Heffernan, T. M., Jarvis, H., Rodgers, J., Scholey, A.B., Ling, J. (2001). Prospective memory, everyday cognitive failure and central executive functioning in recreational users of ecstasy. Human Psychopharmacology, 16, 607-612.

Hinkle, D. E., Wiersma, W., \& Jurs, S. G. (1994). Applied Statistics for the Behavioral Sciences ( ${ }^{\text {rd }}$ Ed.) Boston MA: Houghton Mifflin

Horne, J. A., \& Östberg, O. (1976). A self-assessment questionnaire to determine morningness-eveningness in human circadian rhythms. International Journal of Chronobiology, 4, 97-100.

Jager, G., Kahn, R.S., Van Den Brink, W., Van Ree, J.M., Ramsey, N.F. (2006). Long-term effects of frequent cannabis use on working memory and attention: an fMRI study. Psychopharmacology, 185(3), 358-368.

Jefferies, E., Lambon Ralph, M.A., Baddeley, A.D. (2004). Automatic and controlled processing in sentence recall: The role of long-term and working memory. Journal of Memory and Language, 51(4), 623-643.

Johns, M. W. (1991). A new method for measuring daytime sleepiness: the Epworth Sleepiness Scale. Sleep, 14(540-545).

Kanayama, G., Rogowska, J., Pope, H.G., Gruber, S.A., \& Yurglun-Todd, D.A. (2004).

Spatial working memory in heavy cannabis users: a functional magnetic resonance imaging study. Psychopharmacology, 176(3-4), 239-247.

Kopp, B., Rist, F., \& Mattler, U. (1996). N200 in the flanker task as a neurobehavioural tool for investigating executive control. Psychophysiology, 33, 282-294.

Luck, S. J., \& Hillyard, S. A. (1994). Electrophysiological correlates of feature analysis during visual search. Psychophysiology, 31, 291-308. 
McDowell, D. M., \& Kleber, H.D. (1994). MDMA: Its history and pharmacology. Psychiatric Annals, 24(3), 127-130.

Mejias, S., Rossignol, M., Debatisse, D., Streel, E., Servais, L., Guerit, J.M., Philippot, P., Campanella, S. (2005). Event-related potentials (ERPs) in ecstasy (MDMA) users during a visual oddball task. Biological Psychology, 69, 333-352.

Miyake, A., Friedman, N.P., Emerson, M.J., Witzki, A.H., \& Howerter, A. (2000). The unity and diversity of executive functions and their contributions to complex "frontal lobe" tasks: A latent variable analysis. Cognitive Psychology, 41, 49-100.

Montgomery, C., \& Fisk, J.E. (2008). Ecstasy-related deficits in the updating component of executive processes. Human Psychopharmacology, 23, 495-511.

Montgomery, C., Fisk, J.E., Newcombe, R., \& Murphy P.N. (2005). The differential effects of ecstasy/polydrug use on executive components: shifting, inhibition, updating and access to semantic memory. Psychopharmacology, 182, 262-276

Montgomery, C., Fisk, J.E., Wareing, M., \& Murphy, P.N. (2007). Self reported sleep qaulity and cognitive performance in ecstasy users. Human Psychopharmacology, 22, 537-548.

Montgomery, C., Fisk, J.E.,, Wareing, M., Murphy, P.N., \& Newcombe, R (2005). Syllogistic reasoning performance in MDMA (Ecstasy) users. Experimental and Clinical Psychopharmacology, 13(2), 137-145.

Montgomery, C., Hatton, P.N., Fisk, J.E., Ogden, R.S., \& Jansari, A. (2010). Assessing the functional significance of ecstasy-related memory deficits using a virtual paradigm. Human Psychopharmacology, 25, 318-325.

Morgan, M. J. (2000). Ecstasy (MDMA): a review of its possible persistent psychological effects. Psychopharmacology, 152, 230-248.

Murphy, P. N., Wareing, M., Fisk, J.E., \& Montgomery, C. (2009). Executive working memory deficits in abstinent ecstasy/MDMA users: A critical review. Neuropsychobiology, 60, 159-175.

Nieuwenhuis, S., Yeung, N., Widenberg, W., \& Ridderinkhof, R.K. (2003).

Electrophysiological correlates of anterior cingulate function is a go/no-go task: Effects of response conflict and trial type frequency. Cognitive, Affective, \& Behavioural Neuroscience, 3(1), 17-26.

Parrott, A. C. (2004). Is ecstasy MDMA? A review of the proportion of ecstasy tablets containing MDMA, their dosage levels, and the changing perceptions of purity. Psychopharmacology (Berl), 173(3-4), 234-241.

Pazos, A., Prosbit, A., \& Palacios, J.M. (1987). Serotonin receptors in the human brain - III. Autoradiographic mapping of serotonin-1 receptors. Neuroscience, 21(1), 97-122.

Ritter, W., Simson, R., Vaughan, Jr, H.G., \& Macht (1982). Manipulation of event-related potential manifestations of information processing stages. Science, 218(4575), 909-911. 
Rosell, S. L., Bullmore, E.T., Williams, S.C.R., \& David, A.S. (2001). Brain activation during automatic and controlled processing of semantic relations: a priming experiment using lexical-decision. Neuropsychologia, 39, 1167-1176.

Rossi, S., Miniussi, C., Pasqualetti, P., Babiloni, C., Rossini, P.M., \& Cappa, S.F. (2004). Age-related functional changes of prefrontal cortex in long term memory: a repetitive transcranial magnetic stimulation study. The Journal of Neuroscience, 24(36), 7939-7944.

Ruff, R. M., Light, R.H., Parker, S.B., \& Levin, H.S. (1997). The psychological construct of word fluency. Brain and Language, 57, 394-405.

Saykin, A. J., Flashman, L.A., Frutiger, S.A., Johnson, S.C., Mamourian, A.C., Moritz, C.H., O'Jile, J.R., Riordan, H.J., Santulli, R.B., Smith, C.A., \& Weaver, J.B. (1998).

Neuroanatomic substrates of semantic memory impairment in Alzheimer's disease: Patterns of functional MRI activation. Journal of International Neuropsychological Society, 5, 377392.

Shiffrin, R. M., \& Schneider, W. (1977). Controlled and automatic human information processing. Part 2. Perceptual learning, automatic attending and a general theory. Psychol Rev, 84, 127-190.

Stuss, D. T., Alexander, M.P., Hamer, L., Palumbo, C., Dempster, R., Binns, M., Levine, B., \& Izukawa, D. (1998). The effects of focal anterior and posterior brain lesions on verbal fluency. Journal of the International Neuropsychological Society, 4, 265-278.

Suwazono, S., Machado, L., \& Knight, R. T. (2000). Predictive value of novel stimuli modifies visual event-related potentials and behavior. Clinical Neurophysiology, 111, 29-39.

Terman, M., Rifkin, J.B., Jacobs, J., \& White, T.M. (2001). Morningness-Eveningness Questionnaire (Revised). New York, NY: State Psychiatric Institute.

van Veen, V., \& Carter, C.S. (2002). The anterior cingulate as a conflict monitor: fMRI and ERP studies. Physiology \& Behaviour, 77, 477-482.

Verstraete, A. G. (2004). Detection times of drugs or abuse in blood, urine and oral fluid. The Drug Monit, 26(2), 200-205.

Wetherell, M. A., Atherton, K., Grainger, J., Brosnan, R., Scholey, A.B. (2012). The effects of multitasking on psychological stress reactivity in recreational users of cannabis and MDMA. Human Psychopharmacology: Clinical and Experimental, 27(2), 167-176.

Whitney, C., Kirk, M., O'Sullivam, J., Ralph, M.A.L., \& Jeffries, E. (2010). The neural organization of semantic control: TMS evidence for a distributed network in left inferior frontal and posterior middle temporal gyrus. Cerebral Cortex, 10, 1-10.

Yeung, N., \& Cohne, J.D. (2006). The impact of cognitive deficits on conflict monitoring: predictable dissociations between the error-related negativity and N2. Psychological Science, 17(2), 164-171. 
Table 1 - Indices of ecstasy use

\begin{tabular}{lll}
\hline Variable & Mean & S.D \\
\hline Total tablets & 177.65 & 301.73 \\
Last 30 days total & 0.6 & 2.26 \\
Frequency of use (times per & 0.24 & 0.42 \\
week) $(\mathbf{n}=\mathbf{1 2})$ & & \\
\hline
\end{tabular}


Table 2 - Indices sleep quality, fluid intelligence and socio-demographic variables

\begin{tabular}{|c|c|c|c|c|c|c|}
\hline & $\begin{array}{c}\text { Ecstasy } \\
\text { Users }\end{array}$ & & $\begin{array}{c}\text { Polydrug } \\
\text { (non- } \\
\text { ecstasy) }\end{array}$ & & $\begin{array}{c}\text { Drug } \\
\text { Naïve } \\
\text { Controls } \\
\end{array}$ & \\
\hline Males: n, \% & $10(50)$ & & $9(45)$ & & $7(35)$ & \\
\hline & Mean & SD & Mean & SD & Mean & SD \\
\hline Age & 23.94 & 2.50 & 22.58 & 3.45 & 23.10 & 2.94 \\
\hline $\begin{array}{l}\text { University } \\
\text { degree: } \mathrm{n} \\
(\%)\end{array}$ & $14(70)$ & & $12(60)$ & & $11(55)$ & \\
\hline \multicolumn{7}{|l|}{$\begin{array}{l}\text { Employment } \\
\text { status }\end{array}$} \\
\hline $\begin{array}{l}\text { Student; } \mathrm{n}, \\
(\%)\end{array}$ & $12(60)$ & & $14(70)$ & & $17(85)$ & \\
\hline $\begin{array}{l}\text { Employed; } \mathrm{n} \\
(\%)\end{array}$ & $4(20)$ & & $4(20)$ & & $3(15)$ & \\
\hline $\begin{array}{l}\text { Unemployed } \\
\text {; n (\%) }\end{array}$ & $4(20)$ & & $2(10)$ & & $0(0)$ & \\
\hline $\begin{array}{l}\text { Ravens } \\
\text { Progressive } \\
\text { Matrices } \\
\text { (maximum } \\
60 \text { ) }\end{array}$ & 48.68 & 5.96 & 48.35 & 5.83 & 51.35 & 5.01 \\
\hline $\begin{array}{l}\text { Sleep - } \\
\text { Hours/night }\end{array}$ & 7.13 & 1.91 & 7.8 & 1.39 & 7.05 & 1.16 \\
\hline $\begin{array}{l}\text { ESS Score } \\
\text { (maximum } \\
24 \text { ) }\end{array}$ & 6.5 & 3.3 & 6.7 & 3.15 & 6.5 & 3.32 \\
\hline KSS before & 5.05 & 1.93 & 3.75 & 1.48 & 4.79 & 1.23 \\
\hline KSS after & 6.53 & 2.03 & 5.85 & 1.53 & 6.56 & 1.46 \\
\hline MEQ total & 42.10 & $\begin{array}{c}10.1 \\
5\end{array}$ & 45.70 & 9.40 & 47.90 & 8.30 \\
\hline State anxiety & 11.4 & 4.08 & 12.44 & 2.18 & 11.75 & 2.12 \\
\hline State arousal & 19.7 & 4.54 & 20.5 & 3.68 & 20.1 & 3.02 \\
\hline
\end{tabular}


State

13.1

depression
$12.61 \quad 2.4$

12.1

3.14 
Table 3: Indices of drug use other than ecstasy

\begin{tabular}{|c|c|c|c|c|c|c|c|c|c|}
\hline & Mean & SD & $\mathbf{n}$ & Mean & SD & $\mathbf{n}$ & Mean & SD & $\mathbf{n}$ \\
\hline \multicolumn{10}{|l|}{ Cannabis } \\
\hline $\begin{array}{l}\text { Frequency } \\
\text { (times/wk) }\end{array}$ & 2.67 & 3.24 & 12 & 0.95 & 1.9 & 13 & - & - & - \\
\hline $\begin{array}{l}\text { Last } 30 \\
\text { days } \\
\text { (joints) }\end{array}$ & 32.77 & 53.75 & 15 & 6.09 & 15.34 & 17 & - & - & - \\
\hline $\begin{array}{l}\text { Total use } \\
\text { (joints) } \\
\text { Age at } 1^{\text {st }} \\
\text { use }\end{array}$ & 5057.88 & 7504.30 & 16 & 1091.71 & 2531.65 & 19 & - & - & - \\
\hline \multicolumn{10}{|l|}{ Cocaine } \\
\hline $\begin{array}{l}\text { Frequency } \\
\text { (times/wk) }\end{array}$ & 0.15 & 0.14 & 11 & 0.27 & 0.34 & 2 & - & - & - \\
\hline $\begin{array}{l}\text { Last } 30 \\
\text { days } \\
\text { (lines) }\end{array}$ & 0.4 & 1.12 & 15 & 1.60 & 3.58 & 5 & - & - & - \\
\hline $\begin{array}{l}\text { Total use } \\
\text { (lines) } \\
\text { Age at } 1^{\text {st }} \\
\text { use }\end{array}$ & 813.97 & 1940.19 & 16 & 107.30 & 208.43 & 5 & - & - & - \\
\hline \multicolumn{10}{|l|}{ Ketamine } \\
\hline $\begin{array}{l}\text { Frequency } \\
\text { (times/wk) }\end{array}$ & 0.26 & 0.42 & 5 & 0.02 & - & 1 & - & - & - \\
\hline $\begin{array}{l}\text { Last } 30 \\
\text { days use } \\
\text { (grams) }\end{array}$ & 1 & 2.65 & 9 & - & - & - & - & - & - \\
\hline $\begin{array}{l}\text { Total use } \\
\text { (grams) } \\
\text { Age at } 1^{\text {st }} \\
\text { use }\end{array}$ & 31.26 & 70.61 & 11 & 1.13 & 1.62 & 3 & - & - & - \\
\hline $\begin{array}{l}\text { Alcohol } \\
\text { units } \mathrm{p} / \mathrm{w}\end{array}$ & 15.33 & 15.29 & 20 & 10.53 & 8.37 & 20 & 9.93 & 11.58 & 20 \\
\hline
\end{tabular}


Table 4: Amounts of various drug metabolites found in urine samples (mg/L)

\begin{tabular}{llccccc}
\hline & & THC & $\Delta^{9}$ THC & 11-hydroxy- $\Delta^{9}$-THC & 1-Benzylpiperazine & TFMPP \\
\hline E user & N & 3 & 3 & 3 & 1 & 1 \\
& Mean & 0.0083 & 0.16 & 0.003 & 0.84 & 0.18 \\
& SD & 0.01185 & 0.18286 & 0.00346 & - & - \\
Polydrug & N & 1 & 1 & 1 & - & - \\
& Mean & 0.001 & 0.41 & 0.0020 & - & - \\
& SD & - & - & - & - & - \\
Drug & N & - & - & - & - & - \\
Naive & Mean & - & - & - & - & - \\
& SD & - & - & - & - & - \\
\end{tabular}


Table 5: Performance Data (means and SDs of error count and reaction times) for all participants in both conditions.

\begin{tabular}{|c|c|c|c|c|c|c|}
\hline & $\begin{array}{l}\text { Ecstasy } \\
\text { users }\end{array}$ & & $\begin{array}{l}\text { Polydrug } \\
\text { (non } \\
\text { ecstasy) }\end{array}$ & & $\begin{array}{l}\text { Drug } \\
\text { Naive }\end{array}$ & \\
\hline & Mean & SD & Mean & SD & Mean & SD \\
\hline $\begin{array}{l}\text { High } \\
\text { association } \\
\text { errors }\end{array}$ & 4.00 & 2.34 & 4.60 & 2.78 & 5.25 & 2.77 \\
\hline $\begin{array}{l}\text { Low } \\
\text { association } \\
\text { errors }\end{array}$ & 4.10 & 2.57 & 4.60 & 2.09 & 5.35 & 2.92 \\
\hline $\begin{array}{l}\text { High } \\
\text { association } \\
\text { RT (ms) }\end{array}$ & 1282.26 & 255.91 & 1294.43 & 354.77 & 1209.39 & 230.89 \\
\hline $\begin{array}{l}\text { Low } \\
\text { association } \\
\text { RT (ms) }\end{array}$ & 1265.14 & 250.85 & 1294.21 & 308.44 & 1180.39 & 198.60 \\
\hline
\end{tabular}


Table 6: Mean amplitudes across components, for each electrode measured.

\begin{tabular}{|c|c|c|c|c|c|c|c|c|}
\hline \multirow[t]{2}{*}{ User group } & \multicolumn{8}{|c|}{ P3 High Association } \\
\hline & PO7 & PO3 & 01 & $\mathbf{O z}$ & $\mathbf{P O z}$ & PO8 & PO4 & $\mathbf{O 2}$ \\
\hline Ecstasy user (20) & $2.95(4.02)$ & $3.94(2.42)$ & $2.76(3.01)$ & $1.60(3.24)$ & $4.19(2.34)$ & $4.40(3.23)$ & $4.94(2.99)$ & $3.31(3.59)$ \\
\hline Polydrug (20) & $4.12(2.83)$ & $2.97(2.57)$ & $3.52(4.60)$ & $3.04(3.40)$ & $3.28(2.27)$ & $5.72(3.78)$ & $4.05(3.27)$ & $3.32(3.32)$ \\
\hline \multirow[t]{2}{*}{ Drug Naïve (19) } & $3.62(3.19)$ & $3.92(2.39)$ & $2.84(3.17)$ & $2.13(3.14)$ & $3.42(2.56)$ & $5.35(3.40)$ & $4.00(2.21)$ & $3.27(2.75)$ \\
\hline & \multicolumn{8}{|c|}{ P3 Low Association } \\
\hline Ecstasy user (20) & $3.48(3.74)$ & $4.60(2.74)$ & $2.32(3.57)$ & $1.79(2.90)$ & $4.46(2.40)$ & $3.78(2.92)$ & $4.98(3.33)$ & $2.97(3.39)$ \\
\hline Polydrug (20) & $4.16(3.29)$ & $3.44(3.16)$ & $2.27(4.40)$ & $2.70(2.85)$ & $3.89(2.26)$ & $5.92(4.61)$ & $4.41(3.67)$ & $3.14(3.90)$ \\
\hline \multirow[t]{2}{*}{ Drug Naïve (19) } & $4.32(3.42)$ & $4.40(2.64)^{*}$ & $3.08(3.46)$ & $2.22(3.21)$ & $3.93(2.80)$ & $6.07(3.32)$ & $4.54(2.69)$ & $3.78(2.92)$ \\
\hline & \multicolumn{8}{|c|}{ N2 High Association } \\
\hline Ecstasy user (20) & $-1.66(3.41)$ & $-1.32(3.55)$ & $-2.19(3.53)$ & $-2.51(3.45)$ & $-0.70(4.01)$ & $-1.41(3.20)$ & $-1.04(3.69)$ & $-2.17(4.12)$ \\
\hline Polydrug (20) & $-2.06(4.57)$ & $-2.37(2.90)^{*}$ & $-2.41(4.36)$ & $-0.59(4.19)$ & $-0.58(2.42)$ & $-0.09(4.11)$ & $-0.44(2.57)$ & $-1.15(3.44)$ \\
\hline \multirow[t]{2}{*}{ Drug Naïve (19) } & $-0.58(3.11)$ & $0.67(2.95) *$ & $-0.36(3.43)$ & $0.09(3.78)$ & $1.22(3.03)$ & $1.12(3.50)$ & $0.82(3.19)$ & $0.33(3.51)$ \\
\hline & \multicolumn{8}{|c|}{ N2 Low Association } \\
\hline Ecstasy user (20) & $-1.40(3.55)$ & $-0.95(3.76)$ & $-2.76(4.19)$ & $-1.98(3.57)$ & $-0.17(3.62)$ & $-1.56(3.53)^{*}$ & $-1.01(3.67)$ & $-2.40(3.75)^{*}$ \\
\hline Polydrug (20) & $-1.69(4.69)$ & $-1.55(3.15)$ & $-2.11(4.47)$ & $-1.09(3.43)$ & $-0.28(2.16)$ & $-0.22(4.02)$ & $-0.29(1.91)$ & $-0.10(3.71)$ \\
\hline \multirow[t]{3}{*}{ Drug Naïve (19) } & $0.01(3.67)$ & $0.65(2.97)$ & $-0.33(4.07)$ & $-0.99(3.62)$ & $1.55(2.91)$ & $1.30(3.58)^{*}$ & $0.91(2.73)$ & $0.67(3.48)^{*}$ \\
\hline & \multicolumn{8}{|c|}{ P2 High Association } \\
\hline & $\mathbf{F z}$ & $\mathbf{F C z}$ & FC1 & FC2 & $\mathbf{C z}$ & C1 & $\mathrm{C} 2$ & \\
\hline Ecstasy user (20) & $0.55(2.15)$ & $1.49(2.04)$ & $1.15(1.79)$ & $0.86(2.09)$ & $1.91(1.48)$ & $0.89(2.13)$ & $0.77(1.53)$ & \\
\hline Polydrug (20) & $1.07(1.98)$ & $1.85(1.54)$ & $1.28(1.52)$ & $1.05(1.87)$ & $1.53(1.73)$ & $0.87(1.87)$ & $0.40(1.64)$ & \\
\hline \multirow[t]{2}{*}{ Drug Naïve (19) } & $-0.10(2.43)$ & $0.78(2.43)$ & $0.61(1.45)$ & $0.03(2.75)$ & $0.59(2.78)$ & $0.22(2.03)$ & $-0.22(2.72)$ & \\
\hline & \multicolumn{8}{|c|}{ P2 Low Association } \\
\hline Ecstasy user (20) & $0.87(2.59)$ & $1.64(2.39)$ & $1.33(2.54)$ & $0.83(2.75)$ & $1.55(1.97)$ & $1.06(1.45)$ & $0.93(1.40)$ & \\
\hline Polydrug (20) & $0.51(1.42)$ & $1.72(1.62)$ & $1.49(2.81)$ & $0.98(1.74)$ & $1.38(1.77)$ & $0.88(1.99)$ & $0.62(1.79)$ & \\
\hline Drug Naïve (19) & $0.14(1.90)$ & $0.72(2.16)$ & $0.54(1.98)$ & $0.41(1.79)$ & $0.81(2.41)$ & $0.39(2.22)$ & $0.54(1.97)$ & \\
\hline
\end{tabular}


Figure 1. Topographies at midpoints for each component (P2, N2 and P3) in the high association condition.
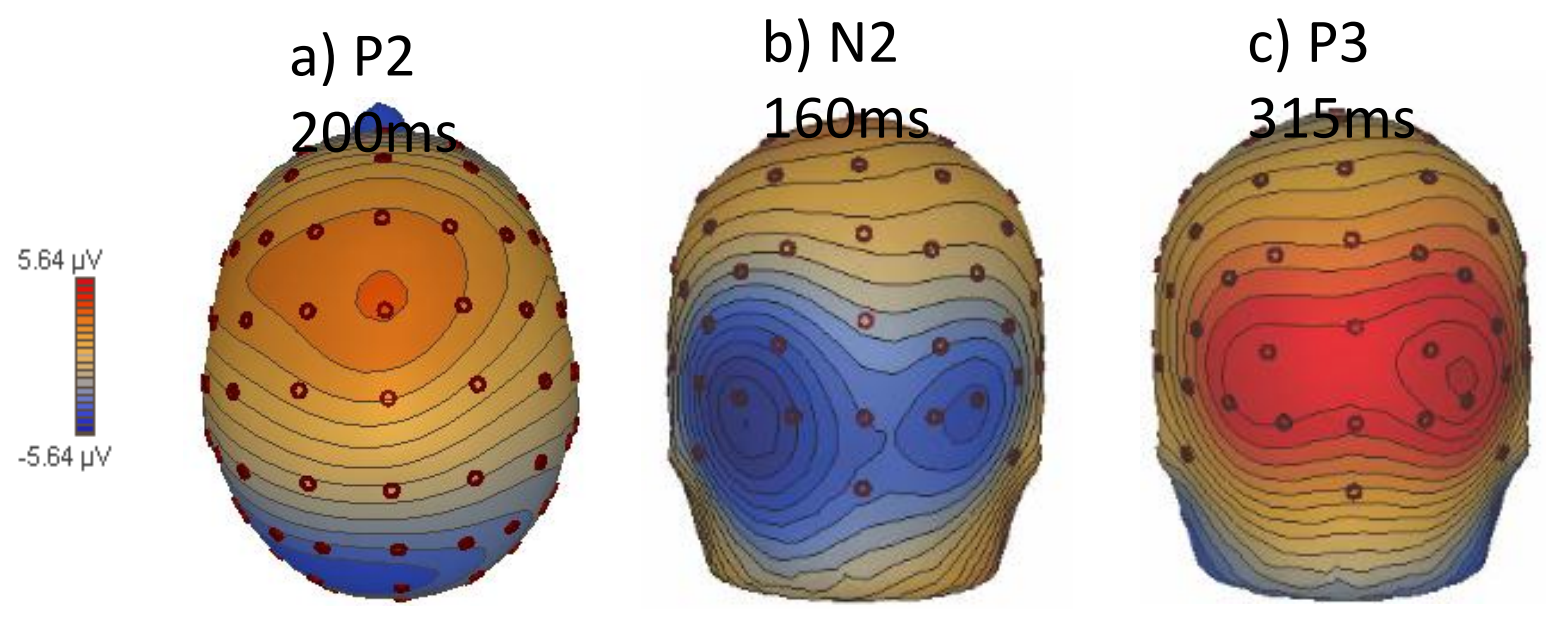

Fig. 1 Shows the topographies for the central point of each component, note that this is from grand averages of each group combined. a) Shows the topography of activity in the epoch specified for the P2 component, note that this component has been isolated at an epoch where there is the most positivity displayed at midline/anterior electrodes b) shows a negativity in N2 notably around posterior and occipital electrodes and c) shows positivity in the P3 component similarly around posterior and occipital electrodes. 
Figure 2. Topographies at midpoints for each component (P2, N2 and P3) in the low association condition.


Fig. 2 Showing the topographies for central points of each component, note that this is from grand averages of each group combined. a) Shows the topography of activity in the epoch specified for the P2 component, b) shows a negativity in N2 notably around posterior and occipital electrodes and c) shows positivity in the P3 component similarly around posterior and occipital electrodes. 
Figure 3. Grand average waveforms for the 3 groups across electrodes: PO3, POz, PO4, PO7, $\mathrm{PO} 8, \mathrm{O} 1, \mathrm{Oz}$ and $\mathrm{O} 2$ on the high association condition of the task.

\section{PO3}

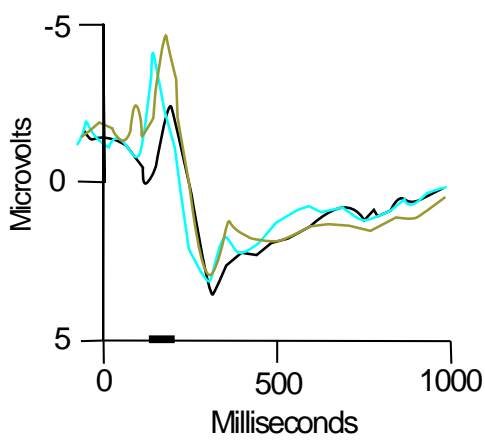

PO7

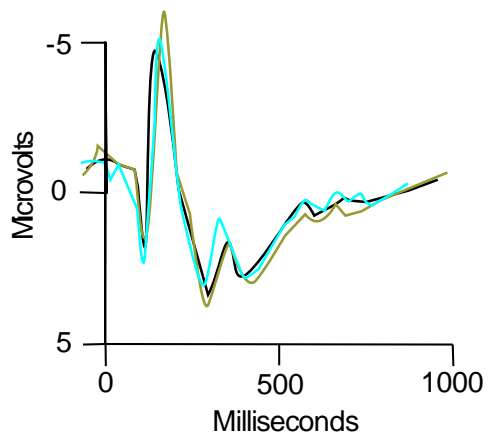

01

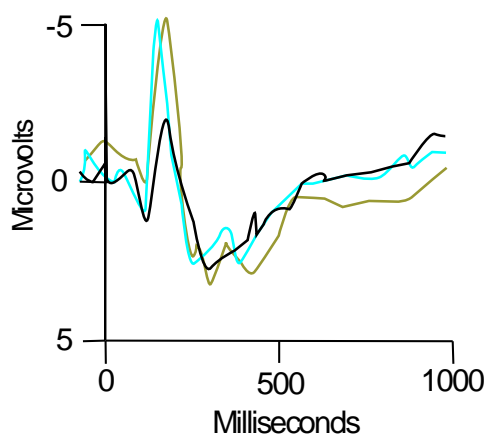

$\mathrm{POz}$

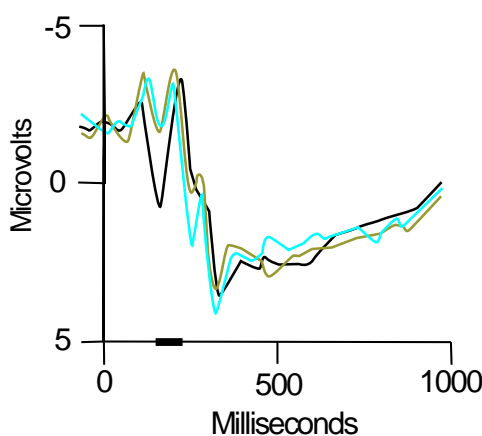

Milliseconds
PO4

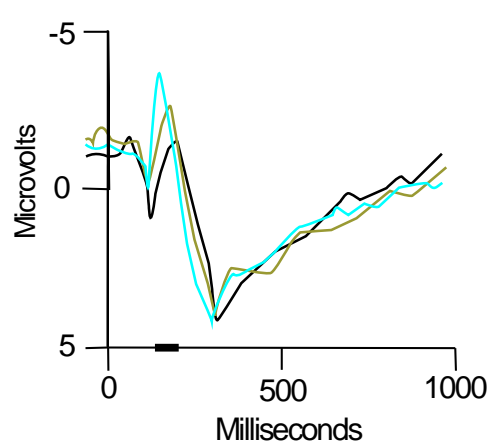

PO8

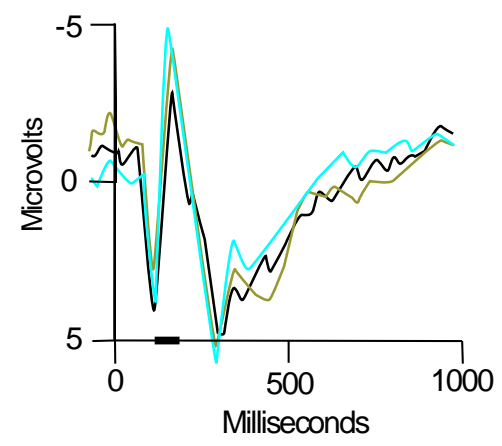

02

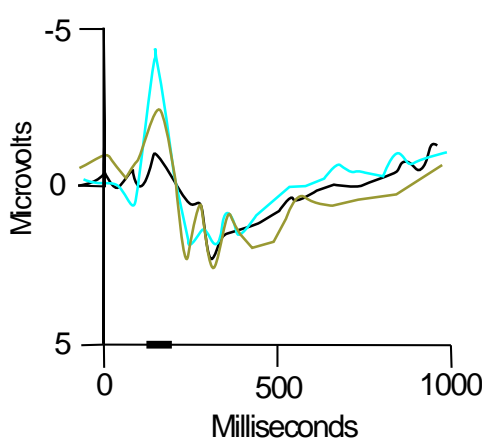

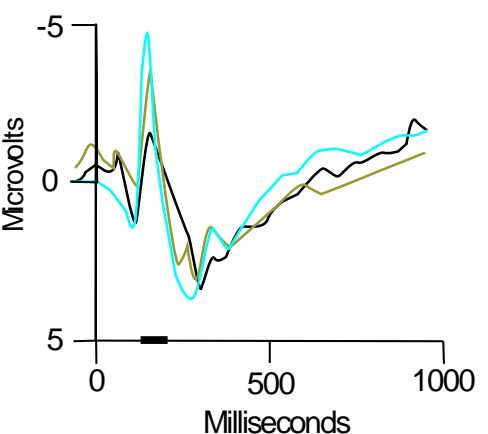

Fig. 3 Depicts the grand average waveforms for each user group from each electrode measured (for the N2 and P3 components) for the high association condition of the task. As such the time course of the various components can be observed.. (ecstasy users shown in blue, polydrug users in green and drug naïve controls in black). Also the magnitude and time course of the significant differences in mean amp in the N2component (120-200ms) between ecstasy users and drug naïve controls can be observed in PO3, POz, PO4, PO8, Oz and $\mathrm{O} 2$. Epochs showing significant differences in the $\mathrm{N} 2$ component are emboldened in black on the $\mathrm{x}$ axis. 
Figure 4. Grand average waveforms for the 3 groups across electrodes: PO3, POz, PO4, PO7, $\mathrm{PO} 8, \mathrm{O} 1, \mathrm{Oz}$ and $\mathrm{O} 2$ on the low association condition of the task.

PO3

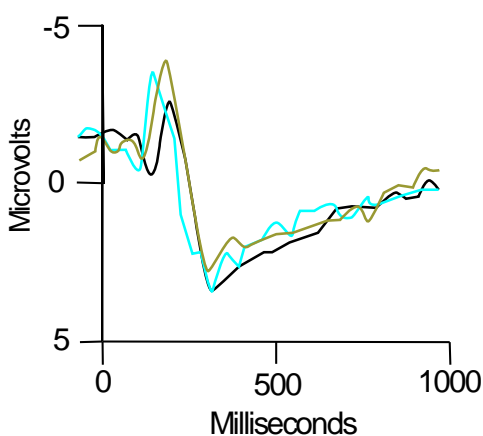

PO7

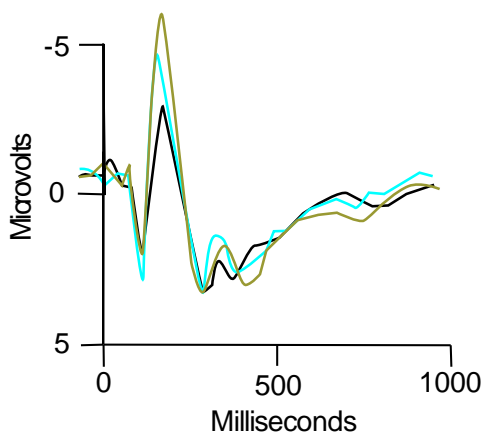

01

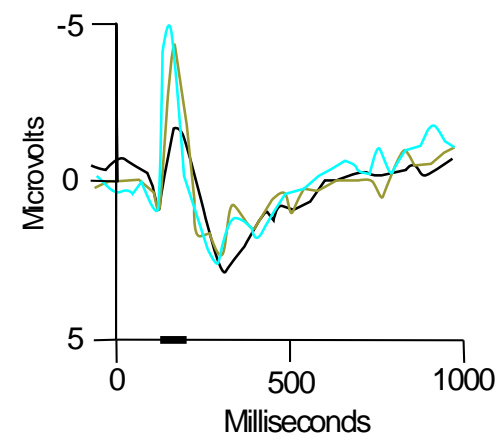

$\mathrm{POz}$

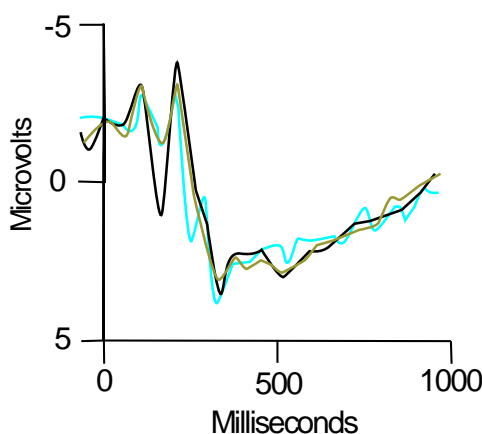

Milliseconds
PO4

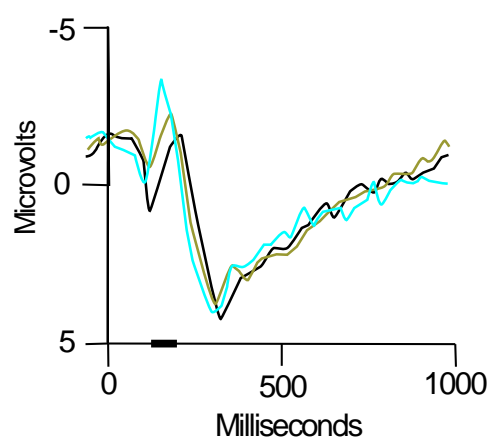

PO8

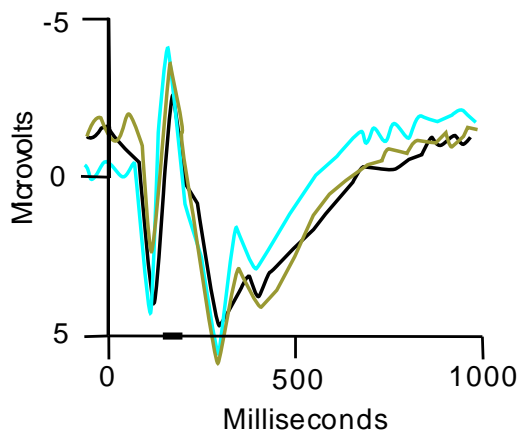

O2

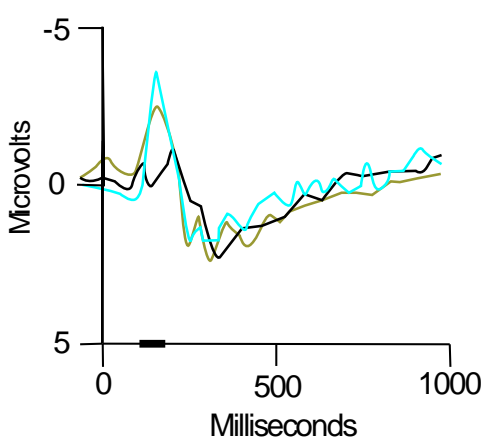

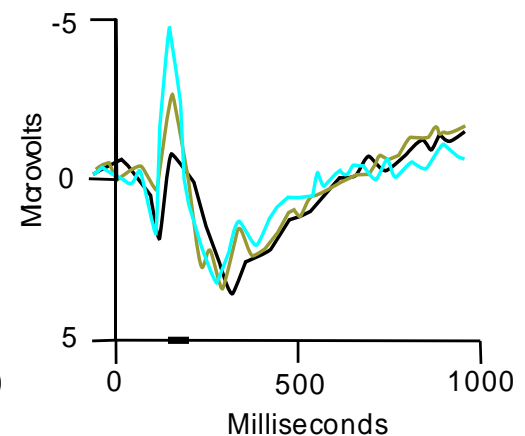

Fig. 4 Depicts the grand average waveforms for each user group (ecstasy user in blue, polydrug users in green and drug naïve controls in black) from each electrode measured (for N2 and P3 components) for the low association condition of the task. The magnitude and time course of the significant differences in mean amp in the N2component (120-190ms) between ecstasy users and drug naïve controls can be observed in PO4, PO8, O1, $\mathrm{Oz}$ and $\mathrm{O} 2$. Epochs showing significant differences are emboldened in black on the $\mathrm{x}$ axis. 